\title{
American Pediatric Society Presidential Address 1991: How Many? How Small?
}

\author{
MARY ELLEN AVERY \\ Ilarvard Medical School, The Children's Hospital, Boston, Massachusetts 02115
}

I have chosen to consider our responsibilities for children in general, as academic leaders of pediatrics, and our special role as practitioners of preventive medicine. My title, "How Many?" refers to the global considerations that couple high birth rates with high infant mortality rates, a theme that will be further developed by our symposium speakers. The remarks headlined "How Small?" refer to our activities as neonatologists in the high technology support for ever-smaller premature infants in our own society and our ongoing responsibilities to meet their needs. I could preface my talk (with what is my conclusion) by saying that it should be the right of every woman to decide when and how often to become pregnant and the right of every child to be wanted.

We are reminded daily that we do indeed live in an ever-more crowded and ever-more divided world. Our recognition of the plight of children born in poverty is not new. Certainly Charles Dickens in the 19th century understood the emotions of children victimized by a society that failed to appreciate either their feelings or their physical needs. And who can forget, in our times, the vivid pictures of children victimized by drought, famine, wars, and disease that are so much a part of our very recent experience. AIDS is the scourge of our generation. It is hardly surprising that Africa, India, and Southeast Asia dominate the higher infant mortality rates, just as they do the higher number of births. North America, Europe, Japan, and portions of South America, Australia, and New Zealand represent the lowest infant mortality rates. The magnitude of the differences perhaps has not been appreciated, since the estimates are that 20 to $40 \%$ of babies born in Ethiopia or Bangladesh die within the first 5 years of life, whereas less than 10 per 1000 infants die before age 5 years in Japan, most of Europe, and the United States and Canada. (The under-5-year mortality, adopted by UNICEF, is most appropriate because so many infant deaths occur during the years of dependence on adult caretakers.)

One aspect of the rationale for emphasizing this topic is to state the obvious; that is, children now alive will, within a few decades, inherit our earth. The awareness of this fact was expressed in remarks attributed to Abraham Lincoln, "You may adopt all the policies you choose, but how they are carried out depends on your children. They are going to assume control of your cities, states and nations. They will take over your churches, schools, universities and corporations. All your works are going to be judged, praised or condemned by them. The fate of humanity is in their hands." My thesis is that one measure of our civilized behavior is our concern about the needs, indeed the rights, of all women and children.

Fortunately, a decrease in infant mortality is usually accompanied by a decrease in birth rate. Much experience supports their association. The capacity of countries to lower infant mortality is most vividly demonstrated by the experience in Japan, where in 194090 deaths per 1000 live births were reported and in 1989 there were 4.4 per 1000 live births. The number of

Correspondence: Mary Ellen Avery, M.D., Thomas Morgan Rotch Professor of Pediatrics, Harvard Medical School. The Children's Hospital, 221 Longwood Avenue, Boston, MA 02115 pregnancies per couple was 4 in 1940 and 1.57 in 1989. The reduction in birth rate in Japan has been attributed by the minister of finance to the physical, psychologic, and economic cost of raising children, as well as the housing problem. I could add additional factors, such as few pregnancies in women under 20 years old and universal access to medical care. A similar trend is evident in our own history, with a fertility rate of 8 per woman in the last century to just under 2 per woman currently. Even so, the population of the United States has doubled in my lifetime. (Parenthetically, from a historical perspective, there may have been some improvement: I've read that Egyptian pharaohs had as many as 5 to 10 offspring per wife.)

It is clear that the world's population is growing logarithmically, especially among those with the least opportunity for access to good medical care or education. The women in Kenya are on the average either pregnant or breast-feeding for 15 to 20 years of their adult life. In most of the developing world, one half the population is under the age of marriage, and the literacy rate is under $50 \%$. The most obvious observation that one makes on visiting a third world country is that children are everywhere, often begging. How do you respond to the swollen impetiginous hand of a child thrust through the window of your taxi? Admittedly, the reasons for the burgeoning increase in population are complex, and the impact of cultural traditions is apparent. I remember speaking with a Kikuyu tribesman in Kenya, surrounded by his 10 children. In response to my question, "Why so many children?" the answer was, "We like children." He might have added that they are his social security. In contrast, the nomadic Eskimo tradition was to have few children; in the event of twins, for example, only the stronger would be nurtured. The experiment with population control of only one child per couple in communist China was dictated by the constraint of food for a population of over 1 billion people, who had to accept zero population growth or even a reduction for long-term survival. However, population control by decree (as in China) is neither as effective nor as desirable as control by choice (as in Japan).

The world's population was approximately 3 billion in 1960 and exceeded 5 billion in 1985. I think it is clear that the annual net increase in the world's population of nearly 100 million per year is intolerable. Complacency or lack of awareness of the magnitude of these problems, particularly as they affect women and children, is also intolerable. One important possible solution will be emphasized by our guest from Paris, Professor Baulieu, the creator of RU 486, a drug that blocks progesterone receptors reversibly, so that it is an effective abortifacient within the first 8 or 9 weeks of pregnancy. This drug must be appreciated in the context of an estimated several hundred thousand maternal deaths per year worldwide, half of which are estimated to be from unsafe abortions. Empowering women to elect when to terminate their pregnancy by medical rather than surgical means would have the impact of saving at least half this number, or about 100000 maternal lives per year. Think about that number: 100000 mothers of untold numbers of infants.

I turn now to the topic "How Small?", because in the developed 
countries we have indeed had to confront a number of challenges, one of which is use of life support interventions, including surfactant replacement therapy, for infants of ever-decreasing birth weight. The outlook for survival for low birth weight babies improves each year. Indeed, 10 to $15 \%$ of infants now born at 23 to 24 weeks can survive, but it is not clear what the price may be in terms of morbidity. In general, infants born before 26 weeks of pregnancy, with weights less than $600 \mathrm{~g}$, are at high risk for significant disability. We are, however, speaking of less than $0.1 \%$ of all births. This lessens the necessity for pronouncements about these babies in general, but promotes the need to consider each one individually. The degree of maturity at a given gestational age is, of course, influenced by race, sex, intrauterine environment, and the health of mother and fetus. It is often easier to reach a reasonable consensus about mobilization of intensive care with all the information about a given infant than it is to devise general guidelines that are often inadequate or inappropriate when applied to a unique situation.

When we consider all infants born weighing less than $1.5 \mathrm{~kg}$ (about $0.3 \%$ of all births), they have about three times the risk of significant difficulties in school as infants born near term. Very low birth weight infants may have other health problems that require ongoing care, such as chronic lung disease and neurologic and visual difficulties. They have five times the rate of major malformations compared to term infants. Their increased susceptibility to severe respiratory syncytial virus infection is well known.

It is also true that very low birth weight infants are often from disadvantaged environments, which must compound the other problems associated with their low birth weight. The question is, "How many of these postnatal problems can be prevented with early intervention?" The answer, fortunately, is maybe as high as one half in some settings. The findings of the infant health and development program, a multisite controlled, randomized trial of intensive educational intervention from ages 1 to 3 years, were presented at these meetings by Dr. Ruth T. Gross last year. She described major improvements in cognitive development and fewer behavior problems among the infants who had a structured intervention program.

An obvious goal in the future is the reduction in the prematurity rate, which unfortunately is higher among the poor and has been relatively stable at 6 to $7 \%$ for the past decade. Very young or very elderly mothers have an increased likelihood of premature onset of labor. Similarly, the prematurity rate is closely associated with maternal habits, such as cigarette smoking and drug addiction, as well as the other complex group of factors associated with poverty. If we ignore or neglect the need to reduce the prematurity rate, we must take responsibility for the ongoing problems of the infants.

Let us consider some of the dilemmas that very premature infants create. Now that surfactant replacement and other therapies for low birth weight infants are here to stay, we will be seeing more and more very low birth weight infants surviving, not all of whom will escape hyaline membrane disease and bronchopulmonary dysplasia. In those who achieve good lung function, no guarantee exists for adequate function of other immature organs. One extreme approach to facing this problem is to take the attitude of those concerned with animal husbandry: let the weaker go. It is, of course, not socially acceptable in this society at this time, and we are unwilling to adopt a policy that dictates behavior for the class of infants not all of whom have the same chances for survival. An opposing extreme scenario is to say that we should do all things for all infants who exhibit a heart beat or any sign of life. Neither extreme view seems wise.

We can consider the unfortunate effects of another extreme policy, to encourage more births. When the Romanians urged women to have as many children as possible and banned birth control and abortions, the nurseries filled with over 30000 abandoned orphans. An unforgettable and horrible scene, illustrative of societal interference with individual decisions.

Another proposal is to let the courts deal with all the thorny issues. This is becoming increasingly the American way. When judges rule that some mothers have committed a felony for delivering cocaine via the umbilical cord to their fetus in utero, we recoil with horror. At least a few such judgments have been overturned, fortunately, because the alternative is penalizing prospective mothers whose burdens are already often overwhelming.

I am not prepared to advocate policies to address these problems at this time, but I think we need to bear in mind the two important principles that I mentioned earlier. One is to ask what women want, and I think the answer is obvious. They want to choose when and how often to become pregnant. Our next question is, "What is in the best interest of the child?" And I think the answer is, as Planned Parenthood proposes, that it should be the right of every child to be wanted. In this society, at this time, we have the knowledge to put the control of reproduction in the hands of women and to improve the outcome of pregnancy and the postnatal environment for each child. When are we going to do it?

I quote from Donald Langenberg's Presidential Address to the American Association for the Advancement of Science on February 17, 1991:

Engagement in the great societal issues of our times requires a willingness to accept risk both individual and collective. It is neither easy nor safe. The role of the objective and disengaged observer and critic is a far more comfortable one. There is a big difference between coaching or playing in the Super Bowl and analyzing the game from the press box. But if science and technology are as critical to the nation's welfare as we say they are, then scientists and engineers need to be in the game, not on the sidelines.

This may not be the time for a policy, but surely it is the time for an open discussion of the issues, and that is the purpose of the Presidential Symposium.

Walt Whitman had some wise words on these issues in his Song of the Open Road. "It is provided in the essence of things that from any fruition of success, no matter what, shall come forth something to make a greater struggle necessary." 